Supporting information for:

\title{
A Comprehensive Study of the Ceria-H2 System: Effect of the Reaction Conditions on the Reduction Extent and Intermediates
}

D. Schweke ${ }^{1 *}$, L. Shelly ${ }^{2}$, R. Ben David ${ }^{3}$, A. Danon ${ }^{1}$, N. Kostirya ${ }^{1}$ and S. Hayun ${ }^{2}$

1. Nuclear Research Centre- Negev, Beer-Sheva 84190, Israel.

2. Department of Materials Engineering, Ben-Gurion University of the Negev, P.O. Box 653, Beer-Sheva 84105, Israel.

3. Israel Atomic Energy Commission, Tel-Aviv, Israel

*Corresponding author

1. XRD patterns collected before and after reduction

XRD patterns of the ceria powder were collected before and after reduction experiments. A representative XRD pattern recorded following reduction at $500^{\circ} \mathrm{C}$, with $4 \% \mathrm{H}_{2}$ is shown in Figure $\mathrm{S} 1$. It can be seen that ceria remained fluorite following reduction, and the lattice parameter remained nearly unchanged (slightly increased).

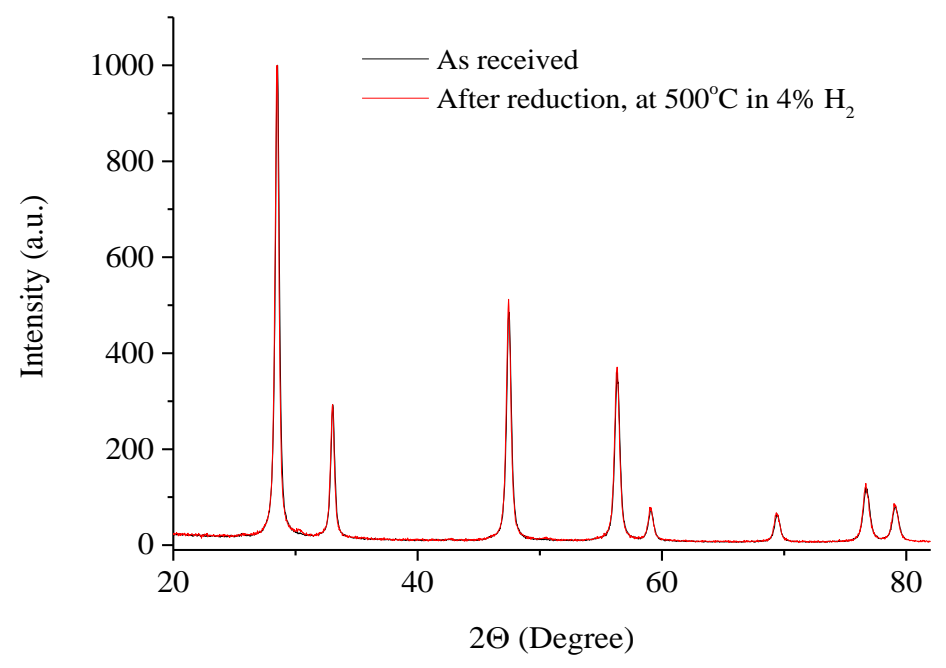


Figure S1: XRD pattern of ceria powder, as received and after reduction at $500^{\circ} \mathrm{C}$, in $\mathrm{pH}_{2}=410^{-2} \mathrm{~atm}$.

\section{Analysis of the TPR curves}

The $\mathrm{H}_{2} \mathrm{O}$ profiles shown in Figure 3 were obtained by subtracting from the raw $\mathrm{H}_{2} \mathrm{O}$ TPR spectra, the $\mathrm{H}_{2} \mathrm{O}-\mathrm{TPD}$ profiles obtained with pure $\mathrm{He}$, at the same heating rate. The $\mathrm{H}_{2} \mathrm{O}-\mathrm{TPD}$ profiles can be attributed to the desorption of residual surface adsorbed $\mathrm{H}_{2} \mathrm{O}$. The raw $\mathrm{H}_{2} \mathrm{O}-\mathrm{TPR}$ (solid blue) and the $\mathrm{H}_{2} \mathrm{O}-\mathrm{TPD}$ (dashed blue) profiles are shown for example in Figure 2, for the heating rate of $25^{\circ} \mathrm{C} / \mathrm{min}$.

The activation energy for $\mathrm{H}_{2} \mathrm{O}$ desorption $\left(\mathrm{E}_{\mathrm{a}}\right)$ has been evaluated from the observed shift of peak temperature with increasing applied heating rate, using the Kissinger equation:

$\ln \left(\frac{\beta}{T_{p}^{2}}\right)=-\frac{E_{a}}{R} \cdot \frac{1}{T_{p}}+\ln \left(\frac{R A}{E_{a}}\right)(1)$

where $\beta$ is the heating rate, $T_{p}$ is the temperature at which the maximum $\mathrm{H}_{2} \mathrm{O}$ desorption rate is obtained, $\mathrm{A}$ is the pre-exponential factor and $\mathrm{R}$ is the gas constant.

3. Estimation of the ceria sub-stoichiometry achieved by thermal reduction

To determine the sub-stoichiometry in ceria thermally reduced under UHP Ar at different temperatures, separate thermo-gravimetric experiments were performed on relatively high sample quantities $(\sim 0.5 \mathrm{~g})$. The results of two successive red-ox cycles, performed at two different temperatures $\left(500^{\circ} \mathrm{C}\right.$ and $\left.600^{\circ} \mathrm{C}\right)$ are represented in Figure S2. The oxygen sub-stoichiometry $\delta$ achieved following thermal reduction was deduced from the mass change recorded thermo-gravimetrically using:

$$
\delta_{\mathrm{f}}-\delta_{\mathrm{i}}=\frac{m_{f}-m_{i}}{m_{i}} \frac{M_{\mathrm{CeO} 2}}{M_{O}}
$$

where $\mathrm{m}_{\mathrm{i}}$ and $\mathrm{m}_{\mathrm{f}}$ are the initial mass (after degassing at $400^{\circ} \mathrm{C}$ ) and the final mass, at the end of the thermal reduction stage, respectively. Assuming $\delta_{\mathrm{i}}=0$, i.e. the ceria powder was stoichiometric after degassing, the sub-stoichiometries obtained are $\delta \sim 0.007$ and $\delta \sim 0.013$ for thermal reduction at $500^{\circ} \mathrm{C}$ and $600^{\circ} \mathrm{C}$, respectively. 


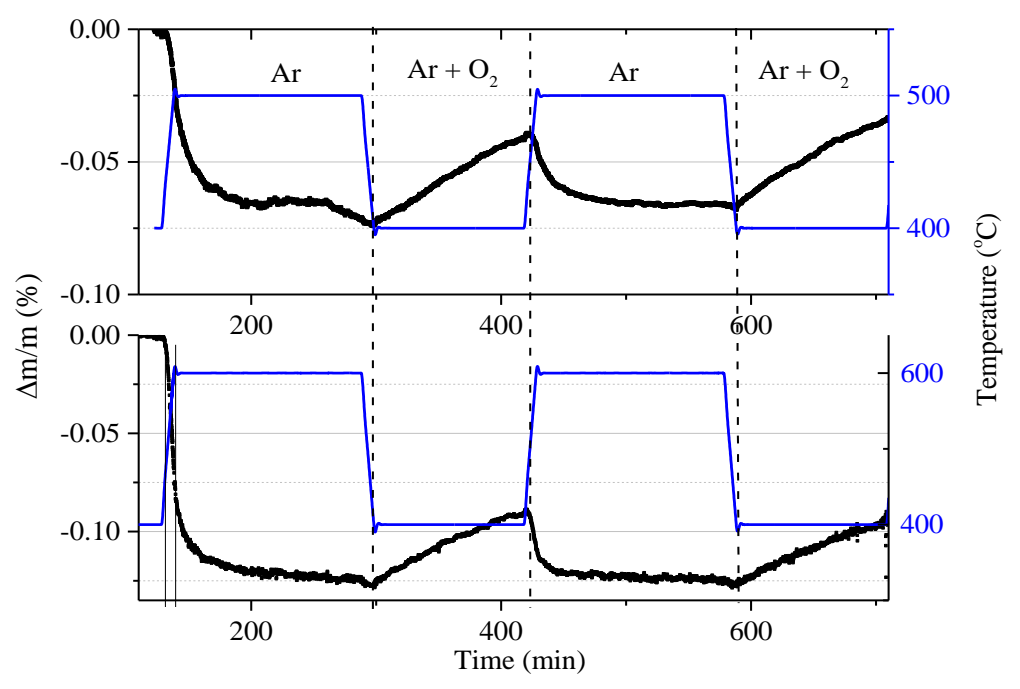

Figure S2: TG signal recorded during two consecutive cycles of thermal reductionoxidation of ceria, at two different temperatures.

4. Reactions involved in the ceria Red-Ox cycle

Figure S3 represents the different steps in the reduction of ceria by $\mathrm{H}_{2}$ (clockwise) or by heating (counter-clockwise) and in the subsequent re-oxidation by $\mathrm{O}_{2}$ or $\mathrm{H}_{2} \mathrm{O}$. The defects formed in ceria are represented in each step in Kroger Vink notation.

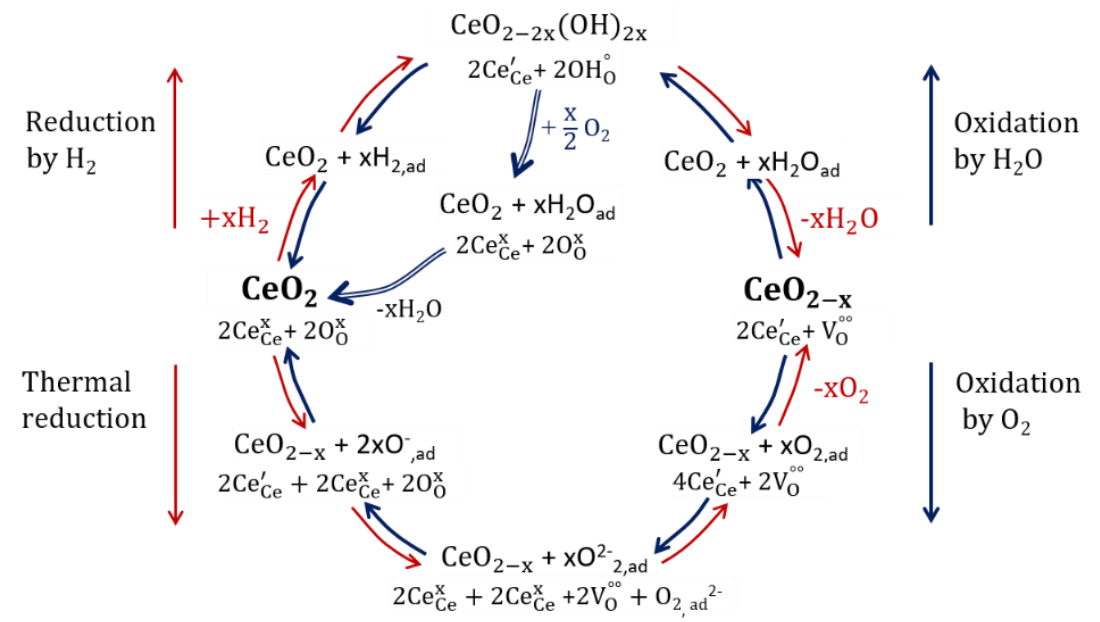

Figure S3: Schematic scheme of the steps in the reduction of ceria by $\mathrm{H}_{2}$ (clockwise) or by heating (counter-clockwise) and in the subsequent re-oxidation by $\mathrm{O}_{2}$ or $\mathrm{H}_{2} \mathrm{O}$. 